\title{
Reduced blocking as a result of increasing the number of blocking cues
}

\author{
James E. Witnauer, Gonzalo P. Urcelay, and Ralph R. Miller \\ State University of New York, Binghamton, New York
}

\begin{abstract}
Weak behavioral control (blocking) occurs when a target stimulus (X) is paired with an outcome in the presence of a well-established signal for the outcome (i.e., a blocking stimulus). Conventional Pavlovian conditioning theories explain this effect by asserting that a discrepancy between expected and experienced outcomes is necessary for learning about $\mathrm{X}$ and that no such discrepancy exists in blocking situations. These theories anticipate that the effect of additional well-established signals for the unconditioned stimulus (US) should be additive. In two conditioned barpress suppression experiments using rats as subjects, the opposite result was observed. Experiment 1 provided evidence that blocking was reduced when two blocking stimuli were present during X-US pairings relative to when one blocking stimulus was present. Experiment 2 elaborated on the mechanisms underlying the observations in Experiment 1, while explaining the discrepancy between the results of Experiment 1 and prior reports of the additivity of blocking stimuli.
\end{abstract}

In Pavlovian conditioning situations in which a target stimulus $(\mathrm{X})$ is conditioned in the presence of a companion stimulus (A), competition between $\mathrm{A}$ and $\mathrm{X}$ for behavioral control is often observed. Considerable theoretical work has focused on the mechanisms that underlie cue competition. Two assumptions are common to most learning theory accounts of cue competition (e.g., Rescorla \& Wagner, 1972) and neural network models of learning (e.g., Rumelhart, Hinton, \& Williams, 1986). First is the assumption that expectation of the unconditioned stimulus (US) is based on summation of the expectation evoked by each conditioned stimulus (CS) present on a given trial. Second is the assertion that a discrepancy between expected and experienced USs (i.e., predictive error) is necessary for, and directly related to, changes in the strength of the CS-US association. Predictive error can be expressed formally as $\lambda-V_{\text {total }}$, where $\lambda$ represents the magnitude of an experienced US and $V_{\text {total }}$ represents US expectation based on information provided by all CSs present. Hereafter, we refer to these theories as total error reduction (TER) theories because error is assumed to be based on the total predictive error across a stimulus compound, and associative learning serves to reduce error. Among the most prominent examples of cue competition is blocking, in which conditioned responding to $\mathrm{X}$ as a result of AX-US pairings is attenuated by previous A-US pairings (Kamin, 1968). TER theories explain blocking by asserting that the presence of A during X-US trials reduces predictive error and consequently reduces learning about $\mathrm{X}$.

The extended comparator hypothesis (ECH; Denniston, Savastano, \& Miller, 2001; Stout \& Miller, 2007) is a the- ory that rejects the view that total error across a stimulus compound drives learning and asserts that cue interactions are attributable to retrieval processes that are catalyzed by within-compound associations. Critically, this model assumes that conditioned responding to $\mathrm{X}$ at test is related directly to the difference between the US representation activated through the $\mathrm{X}-\mathrm{US}$ association and that which is activated through the $\mathrm{X}-\mathrm{A}$ and $\mathrm{A}-\mathrm{US}$ associations. Within this framework, responding to $\mathrm{X}$ is inversely related to both the $\mathrm{X}-\mathrm{A}$ and $\mathrm{A}-\mathrm{US}$ associations. Applied to situations where more than one nontarget stimulus was present during training (e.g., counteraction situations), ECH asserts that a nontarget associate of A (i.e., B) can compete with A for the potential to compete with X. Presumably, competition between associates of X (X's comparator stimuli) depends on the within-compound association between these comparator stimuli, just as competition between $\mathrm{X}$ and comparator stimuli depends on withincompound associations. Because the extended comparator hypothesis assumes that two nontarget associates of $\mathrm{X}$ can compete for the potential to reduce responding to $\mathrm{X}$, the model anticipates that two response-degrading treatments can counteract each other in some situations. Recent data offer strong support for this prediction. For example, we have shown that, if $\mathrm{X}$ is simultaneously subjected to two cue-competition treatments (e.g., degraded contingency [unsignaled USs interspersed between the X-US pairings] and overshadowing [A being presented during X presentations]), cue competition is attenuated relative to when $\mathrm{X}$ is subjected to either treatment alone (Urcelay \& Miller, 2006). We refer to these effects as counteraction effects because the two competing cues seemingly counteract

R. R. Miller, rmiller@binghamton.edu 
each other in their potentials to compete with $\mathrm{X}$ for behavioral control (for a review, see Wheeler \& Miller, in press), thereby resulting in stronger conditioned responding than with either competitor alone. Such effects are inconsistent with TER theories because, all other things being equal, additional cue competition treatments should yield more US expectation during X-US pairings, which should reduce excitatory learning about $\mathrm{X}$.

One limitation of all prior demonstrations of counteraction is that the training context has always served as one of the two competing cues. For example, in Urcelay and Miller's (2006) report of counteraction between degraded contingency and overshadowing treatments, the training context was assumed to compete with the overshadowing CS for the potential to reduce responding to X (because the degraded contingency treatment strengthened the context-US association). Moreover, in each instance of counteraction, TER theories anticipate only reduced excitatory learning about $\mathrm{X}$, rather than robust inhibitory learning, because the competing cues are always trained together, which ensures that neither has been trained to the asymptote that would be reached had they been trained separately. The aim of the present experiments was twofold. First, we sought to determine whether two discrete CSs would counteract each other in their potential to compete with X, thereby testing the generality of ECH's account of counteraction effects to situations in which neither competing stimulus is the training context. Second, we sought to determine whether enhanced responding to $\mathrm{X}$ could be observed when the expected US was vastly greater than the experienced US on X-US trials, and thus whether inhibitory learning would be anticipated by TER theories. We investigated these predictions by using a blocking procedure with two independently trained blocking CSs ( $A$ and $\mathrm{B}$ ) to determine whether they would counteract in their potential to compete with $\mathrm{X}$.

\section{EXPERIMENT 1}

To test the hypothesis that blocking would be affected by the number of blocking stimuli present during X-US pairings, a $2 \times 2$ factorial design was used (see Table 1 ). The first factor was whether blocking stimuli (A and B) or control stimuli (C and $\mathrm{D})$ were paired with the US during

Table 1

Design Summary of Experiment 1

\begin{tabular}{lclcc}
\hline \multicolumn{1}{c}{ Group } & \multicolumn{1}{c}{ Phase 1 } & \multicolumn{1}{c}{ Phase 2 } & Baseline & Test X \\
\hline Ctrl-AX & 12 C-US/12 D-US & 6 AX-US & 8.17 & CR \\
Ctrl-ABX & 12 C-US/12 D-US & 6 ABX-US & 8.92 & CR \\
Block-AX & 12 A-US/12 B-US & 6 AX-US & 5.83 & cr \\
Block-ABX & 12 A-US/12 B-US & 6 ABX-US & 7.83 & $?$ \\
\hline
\end{tabular}

Note-CSs A, B, C, and D were 10-sec white noise, tone, flashing light, and turning off of the houselight, counterbalanced within groups as completely as possible such that two visual or more than two auditory CSs were never presented together. CS X was a 10-sec click train. The US was a 0.5 -sec, $1.0-\mathrm{mA}$ footshock. Slashes denote interspersed trials within sessions. CR (cr) denotes a strong (weak) expected conditioned response. Baseline $=$ mean number of leverpresses emitted across the 30 -sec, pre-CS period prior to the first target stimulus presentation during the test session.
Phase 1 (blocking [Block] vs. control [Ctrl]). The second factor was whether one or two previously independent stimuli were present during Phase $2 \mathrm{X}$-US pairings (AX vs. ABX).

\section{Method}

Subjects. Subjects were 24 female and 24 male SpragueDawley, experimentally naive, young adult rats. Body weights were 144-193 g for females and 193-205 g for males. Subjects were housed individually and maintained on a 16:8-h light:dark cycle, with experimental sessions occurring roughly midway through the light portion. Subjects had free access to food in the home cage. Before the experiment, water availability was reduced progressively to 20 min per day, provided soon after scheduled treatments.

Apparatus. The apparatus consisted of 12 chambers, each measuring $30 \times 30 \times 27 \mathrm{~cm}(1 \times \mathrm{w} \times \mathrm{h})$. The side walls of each chamber were stainless steel, and the front and back walls and ceiling were clear Plexiglas. The floor was constructed of $0.3-\mathrm{cm}$ diameter rods that allowed delivery of a constant-current $(1.0 \mathrm{~mA} \pm 10 \%)$ foot shock. Each chamber was housed in a dimly lit (No. 1820) environmental isolation chest. Turning off this houselight served as one cue.

Ventilation fans provided a constant 76- $\mathrm{dB}(\mathrm{C})$ background noise. Three $45-\Omega$ speakers mounted inside each environmental chest could deliver a complex tone (500 and $520 \mathrm{~Hz} ; 4 \mathrm{~dB}$ above background), a click train ( $6 \mathrm{~Hz} ; 8 \mathrm{~dB}$ above background), and a white noise (4 $\mathrm{dB}$ above background), respectively. A SonAlert could provide a $1900-\mathrm{Hz}$ tone ( $6 \mathrm{~dB}$ above background). A flashing light $(0.5 \mathrm{sec}$ on $/ 0.5 \mathrm{sec}$ off) could be delivered by a $100-\mathrm{W}$ bulb (nominal at $120 \mathrm{VAC}$, but driven at $60 \mathrm{VAC})$. Stimulus intensities were selected to minimize overshadowing in the control condition.

Context Test was distinct from Context Train in that the grids were covered by a Plexiglas floorplate, and a lever was extended. Context Train was characterized by a different instance of the apparatus, grid floors, and the lever was retracted.

Procedure. Subjects were assigned randomly to one of four groups $(n \mathrm{~s}=12)$ : Block-AX, Ctrl-AX, Block-ABX, and Ctrl-ABX. Subjects were counterbalanced within groups with respect to sex, physical stimuli, and training chambers. Subjects received Pavlovian training (Phases 1 and 2) in Context Train and shaping, reshaping, and testing in Context Test. This served to minimize possible group differences in fear of the test context.

Acclimation and shaping. Before conditioning, a 5-day acclimation and shaping regimen established stable rates of leverpressing for 0.04-cc water reward. Each of these acclimation days involved at least one 60 -min session. To facilitate leverpress training, water delivery was accompanied by a 0.5 -sec SonAlert presentation. On Days 1 and 2, a fixed-time, 2-min schedule of noncontingent water delivery occurred concurrently with a continuous reinforcement schedule. On Day 3, noncontingent water delivery was discontinued. All subjects that recorded fewer than 50 responses on this day were hand-shaped through successive approximation. The sessions on Days 4 and 5 provided water on a variable interval 20-sec (VI-20) schedule. On both of these days, all subjects responded with more than 50 leverpresses in a session. The VI-20 schedule of reinforcement prevailed throughout reshaping and testing.

Preexposure. On Day 6, in one 60-min session in Context Train, subjects were exposed to 2 nonreinforced presentations of $\mathrm{A}, \mathrm{B}$, $\mathrm{C}, \mathrm{D}$, and $\mathrm{X}$ with a 5-min intertrial interval. This was done to minimize configuring during subsequent compound conditioning.

Phase 1. On Days 7-12 in daily 60-min sessions in Context Train, for blocking subjects, A-US and B-US conditioning trials were pseudorandomly interspersed across Phase 1 conditioning sessions, with a mean intertrial interval of $13 \mathrm{~min}$. For control subjects, C and $\mathrm{D}$ were substituted for $\mathrm{A}$ and $\mathrm{B}$.

Phase 2. On Day 13 in a 90-min session in Context Train, subjects in Groups Block-AX and Ctrl-AX were exposed to six AX-US pairings and subjects in Groups Block-ABX and Ctrl-ABX were exposed to six $\mathrm{ABX}$-US pairings. The mean intertrial interval was $13 \mathrm{~min}$. 
Reshaping. On Days 14-16, baseline recovery training on the VI-20 schedule was conducted in Context Test during daily 60-min sessions.

Test $X$. On Day 17, suppression of baseline responding during presentation of CS X was assessed in Context Test. During a 30-min session, each subject received four nonreinforced 30 -sec presentations of CS X with a mean intertrial interval of $5 \mathrm{~min}$. The response rate during the $30-\mathrm{sec}$ period preceding the first CS exposure (pre$\mathrm{CS}$ score) and that during each of the four 30 -sec CS exposures (CS score) were recorded.

A suppression ratio for each subject was calculated by the formula $P /(P+4 Q)$ for Day 16, where $P$ is the number of leverpresses during the four $30-\mathrm{sec} \mathrm{CS}$ presentations and $Q$ is the number of leverpresses during the $30 \mathrm{sec}$ immediately preceding the first test trial. Thus, a suppression ratio of .50 indicates no conditioned suppression; one of .00 indicates complete suppression.

\section{Results and Discussion}

Group means for suppression in the presence of $\mathrm{X}$ are depicted in Figure 1, and group means for baseline responding are indicated in Table 1. A 2 (Phase 1 treatments Block vs. Ctrl) $\times 2$ (Phase 2 treatments ABX vs. AX) ANOVA on baseline levels of responding (i.e., number of leverpresses emitted during the $30 \mathrm{sec}$ before Test Trial 1) detected no main effect or interaction $(p \mathrm{~s}>.10)$. A similar ANOVA was used to analyze suppression ratios. This analysis detected a marginal interaction between Phase 1 and Phase 2 treatments $[F(1,44)=3.08, p<.10]$, but an effect of Phase 1 treatment was detected $[F(1,44)=19.94$, $p<.01]$, which suggests that blocking was observed regardless of Phase 2 treatment. Notably, on the first test trial an interaction between Phase 1 and Phase 2 treatments was observed $[F(1,44)=4.44, p<.05]$, which suggests that blocking can be attenuated when an additional blocking cue is present during AX-US pairings. Planned comparisons based on all four CS test presentations detected a difference between Groups Block-AX and Ctrl$\mathrm{AX}[F(1,44)=19.34, p<.01]$ and a marginal difference between Groups Block-ABX and Ctrl-ABX $[F(1,44)=$ $3.68, p<.07]$, thereby confirming that blocking occurred, at least in the AX condition. Most importantly, a com-

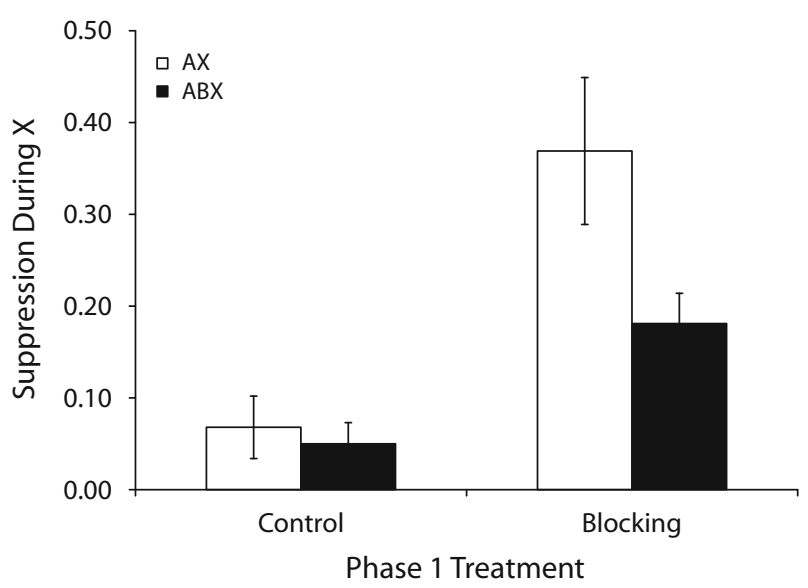

Figure 1. Group mean suppression ratios in the presence of $X$ in Experiment 1. See Table 1 and the text for details. Lower values indicate stronger suppression and higher values indicate weaker suppression. The brackets represent standard errors of the means. The legend indicates treatment during Phase 2. parison between Groups Block-ABX and Block-AX detected a difference $[F(1,44)=7.48, p<.01]$, indicating that blocking was reduced rather than increased with two blocking cues.

The higher conditioned suppression in Group BlockABX relative to Group Block-AX provides support for the predictions of ECH (see the General Discussion for elaboration of the $\mathrm{ECH}$ predictions). In contrast, these results are inconsistent with the predictions of TER theories because US expectation (i.e., $V_{\text {total }}$ ) should have been stronger during ABX-US trials than during AX-US trials. Thus, suppression in Group Block-AX would be predicted to exceed that of Group Block-ABX, which is contrary to what was observed. Moreover, if Phase 1 conditioning was more than halfway to asymptote, which is likely given the rapidity of conditioning with a footshock US and the similarity of our Phase 1 conditioning procedure with prior demonstrations of asymptotic conditioning in our laboratory, then, according to TER theories, the subjects should have acquired an inhibitory $\mathrm{X}-\mathrm{US}$ association during compound conditioning, thereby yielding no suppression to $\mathrm{X}$ in Group Block-ABX. Finally, it should be noted that this is the first study to demonstrate counteraction between two treatments (blocking by A and blocking by $\mathrm{B}$ ) in which both competing stimuli are punctate cues.

The results of Experiment 1 are also inconsistent with prior research on blocking when the compound is overexpected (i.e., the magnitude of the expected US is greater than that of the experienced US) due to the presence of two independently reinforced stimuli (Kremer, 1978; Schachtman, Kasprow, Chee, \& Miller, 1985). Specifically, these studies demonstrated that an overexpected US can result in enhanced blocking, a result that is contrary to the critical finding of Experiment 1. However, examination of these studies reveals an important procedural feature. In these studies, the two blocking stimuli were reinforced on separate trials interspersed among the compound trials during the compound conditioning phase, a treatment that could attenuate the strength of the A-B association that is critical according to $\mathrm{ECH}$, consequently diminishing the counteraction between the blocking stimuli. Notably, one could argue that Phase 1 elemental conditioning of A and $\mathrm{B}$ in the present experiment reduced the strength of the putative $\mathrm{A}-\mathrm{B}$ association, making the $\mathrm{ECH}$ account of Experiment 1 less plausible. Thus, in Experiment 2, we sought to determine whether the A-B within-compound association was important for the observed counteraction between $\mathrm{A}$ and $\mathrm{B}$.

\section{EXPERIMENT 2}

The purpose of Experiment 2 was to determine whether the strength of the association between A and B is an important determinant of blocking when $\mathrm{A}$ and $\mathrm{B}$ are conditioned in compound with $\mathrm{X}$. According to $\mathrm{ECH}$, the strength of the counteraction between $\mathrm{A}$ and $\mathrm{B}$ should be directly related to the strength of the A-B association, and thus responding to $\mathrm{X}$. More specifically, we assessed whether strengthening the association between A and B increases the counteraction between these stimuli, and whether at- 
Table 2

Design Summary of Experiment 2

\begin{tabular}{lcclcc}
\hline \multicolumn{1}{c}{ Group } & \multicolumn{1}{c}{ Phase 1 } & \multicolumn{1}{c}{ Phase 2 } & \multicolumn{1}{c}{ Phase 3 } & Baseline & Test X \\
\hline Inhib-AX & $32 \mathrm{AC} / 32 \mathrm{BC}$ & $12 \mathrm{~A}-\mathrm{US} / 12 \mathrm{~B}-\mathrm{US}$ & $6 \mathrm{AX}-\mathrm{US}$ & 7.75 & $\mathrm{cr}$ \\
Inhib-ABX & $32 \mathrm{AC} / 32 \mathrm{BC}$ & $12 \mathrm{~A}-\mathrm{US} / 12 \mathrm{~B}-\mathrm{US}$ & $6 \mathrm{ABX}-\mathrm{US}$ & 8.00 & $\mathrm{cr}$ \\
None-AX & $32 \mathrm{AD} / 32 \mathrm{BC}$ & $12 \mathrm{~A}-\mathrm{US} / 12 \mathrm{~B}-\mathrm{US}$ & $6 \mathrm{AX}-\mathrm{US}$ & 6.92 & $\mathrm{cr}$ \\
None-ABX & $32 \mathrm{AD} / 32 \mathrm{BC}$ & $12 \mathrm{~A}-\mathrm{US} / 12 \mathrm{~B}-\mathrm{US}$ & $6 \mathrm{ABX}-\mathrm{US}$ & 8.50 & $\mathrm{Cr}$ \\
Excite-AX & $32 \mathrm{AB} / 32 \mathrm{CD}$ & $12 \mathrm{~A}-\mathrm{US} / 12 \mathrm{~B}-\mathrm{US}$ & $6 \mathrm{AX}-\mathrm{US}$ & 7.67 & $\mathrm{cr}$ \\
Excite-ABX & $32 \mathrm{AB} / 32 \mathrm{CD}$ & $12 \mathrm{~A}-\mathrm{US} / 12 \mathrm{~B}-\mathrm{US}$ & $6 \mathrm{ABX}-\mathrm{US}$ & 7.75 & $\mathrm{CR}$ \\
\hline
\end{tabular}

Note-CSs A, B, C, and D were white noise, tone, flashing light, and buzzer presentations, counterbalanced within groups as completely as possible. CSs A, B, C, and D were 10 sec in duration during Phases 2 and 3, but $60 \mathrm{sec}$ during Phase 1. CS X was a 10-sec click train. The US was a $0.5-\mathrm{sec}, 1.0-\mathrm{mA}$ footshock. Slashes denote interspersed trials within sessions. On the basis of simulations of ECH, CR, Cr, and cr denote strong, intermediate, and weak levels of expected conditioned responding. Baseline $=$ mean number of leverpresses emitted across the $30-\mathrm{sec}$, pre-CS period prior to the first target stimulus presentation during the test session.

tenuating the strength of the $\mathrm{A}-\mathrm{B}$ association attenuates the counteraction. To strengthen the association between $\mathrm{A}$ and $\mathrm{B}$, we repeatedly presented $\mathrm{A}$ and $\mathrm{B}$ in compound prior to conditioning. To retard the subsequent development of an A-B within-compound association during ABX-US trials, we exposed subjects to compound presentations of the blocking CSs with another (common) neutral cue (i.e., $\mathrm{AC}-/ \mathrm{BC}-$ ). Prior research (e.g., Espinet, Iraola, Bennett, \& Mackintosh, 1995) suggests that interspersed presentations of two compounds with a common element yields inhibitory learning between the unique elements (i.e., an inhibitory association between A and B), which could be viewed as analogous to the interspersed elemental A-US and B-US trials in Kremer (1978) and Schachtman et al. (1985). In a control condition, (none) A and B were in this initial phase made neither excitatory nor inhibitory with respect to each other. Thus, Experiment 2 used a $3 \times 2$ between-subjects design (see Table 2). The first factor was the Phase 1 preexposure treatment (excite vs. none vs. inhibitory $[$ inhib]), which was intended to be a systematic manipulation of the A-B association. The second factor was the Phase 3 treatment, which was the same as the Phase 2 treatment in Experiment 1 (AX vs. ABX).

\section{Method}

Subjects. Subjects were 36 female (170-214 g) and 36 male (240-330 g) rats, maintained as in Experiment 1.

Apparatus. The preparation was identical to that of Experiment 1, with one exception. In Experiment 2, the houselight-off presentations were replaced with buzzer presentations at $6 \mathrm{~dB}$ above background.

Procedure. Subjects were randomly assigned to one of six groups $(n s=12)$ : None-AX, Inhib-AX, Excite-AX, None-ABX, Inhib$\mathrm{ABX}$, and Excite-ABX. Shaping, preexposure, reshaping, and testing were the same as in Experiment 1.

Phase 1. On Days 7-14, two different schedules ( $\alpha$ and $\beta$ ) were used on alternate days in Context Train. Groups None-AX, NoneABX, Inhib-AX, and Inhib-ABX were exposed to four daily, nonreinforced presentations of the $\mathrm{BC}$ compound interspersed either with four daily, nonreinforced presentations of the $\mathrm{AC}$ compound (Groups Inhib-ABX and Inhib-AX) or four daily, nonreinforced presentations of the AD compound (Groups None-ABX and NoneAX). Groups Excite-ABX and Excite-AX were exposed to four daily, nonreinforced compound presentations of $A B$ interspersed with four daily, nonreinforced presentations of $\mathrm{CD}$, which temporally corresponded to $\mathrm{AC}$ and $\mathrm{BC}$ trials. In schedule $\alpha, \mathrm{AC}, \mathrm{AD}$, or $\mathrm{AB}$ compound presentations occurred at $11,26,35$, and 50 min into the 60-min session, whereas the $\mathrm{BC}$ or $\mathrm{CD}$ compound presentations occurred at 5, 19, 30, and 44 min. In schedule $\beta$, the $\mathrm{AC}, \mathrm{AD}$, or $\mathrm{AB}$ compound presentations occurred at $8,23,33$, and $47 \mathrm{~min}$ into the 60-min session, whereas the $\mathrm{BC}$ or $\mathrm{CD}$ compound presentations occurred at $15,28,40$, and $54 \mathrm{~min}$.

Phases 2 and 3. Phase 2 was conducted the same way as Phase 1 of Experiment 1, except that all subjects were exposed to A-US and B-US trials. Phase 3 was identical to Phase 2 of Experiment 1.

\section{Results and Discussion}

Group means for suppression in the presence of X during the test session are depicted in Figure 2 and group means for baseline responding are presented in Table 2. A 3 (excite vs. none vs. inhib) $\times 2$ (AX vs. ABX) ANOVA on baseline levels of responding during testing failed to detect any main effects or interactions $(p s>.41)$. A similar ANOVA on the suppression ratios detected an interaction between Phase 1 and Phase 3 treatments $[F(2,66)=3.89$, $p<.05]$, which in conjunction with Figure 2 suggests that Phase 1 treatments impacted responding in the ABX, but not the AX groups. Planned comparisons were conducted to determine the source of this interaction. First, a comparison between Groups None-ABX and None-AX de-

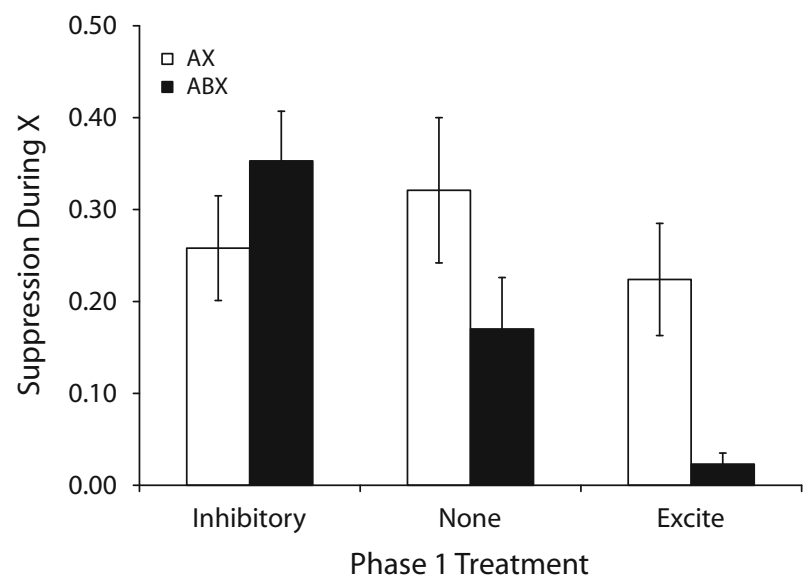

Figure 2. Group mean suppression ratios in the presence of $X$ in Experiment 2. See Table 2 and the text for details. Lower values indicate stronger suppression and higher values indicate weaker suppression. The brackets represent standard errors of the means. The legend indicates treatment during Phase 3. 
tected a reliable difference (one-tailed) $[F(1,66)=3.48$, $p<.05$ ], thereby basically replicating the central finding from Experiment 1 with no relationship between A and $\mathrm{B}$ prior to the compound blocking trials. Second, a difference between Group None-ABX and Inhib-ABX was detected $[F(1,66)=5.16, p<.05]$, suggesting that pretraining an inhibitory relationship between the two blocking cues attenuated their counteraction and thus increased the blocking effect. Moreover, a marginal difference between Groups None-ABX and Excite-ABX was detected $[F(1,66)=3.36, p<.05]$ (one-tailed), which suggests that strengthening the association between $\mathrm{A}$ and $\mathrm{B}$ increased the effectiveness of X-US pairings (i.e., counteraction) in the ABX condition. The difference between Groups Inhib-ABX and Excite- $\mathrm{ABX}$ was significant $[F(1,66)=$ $16.85, p<.01]$.

\section{GENERAL DISCUSSION}

The results of the present experiments suggest that $\mathrm{X}$-US pairings are more effective when they occur in the presence of two independently trained blocking stimuli than in the presence of one blocking stimulus. These results are in opposition to the predictions offered by TER theories of learning, which assert that, on any given trial, learning is directly related to the discrepancy between expected and experienced USs, such that inhibitory learning occurs when the US is overexpected and excitatory learning occurs when the US is underexpected. Applied to the present experiments, TER theories predict that acquisition of an excitatory X-US association should have been impaired in Group Block-ABX relative to Group Block-AX. Moreover, given so many A-US and B-US trials (12 each), A and B should have been near asymptote and consequently an inhibitory X-US should have been promoted by the overexpected US during ABX-US trials, which is inconsistent with the results of Experiments 1 and 2. Moreover, the results of Experiment 2 suggest that this relative response enhancement in Group Block$\mathrm{ABX}$ depends on the status of the association between $\mathrm{A}$ and B. Specifically, prior establishment of a strong A-B association through repeated A-B pairings was shown to increase conditioned suppression to $\mathrm{X}$, whereas repeated interspersed presentations of $\mathrm{AC}$ and $\mathrm{BC}$ were shown to attenuate suppression to X. Given this result, the discrepant reports of counteraction between response degrading treatments (e.g., Urcelay \& Miller, 2006) and reports of summation between response degrading treatments (e.g., Kremer, 1978) can be accounted for within a single framework. ECH (Denniston et al., 2001) asserts, seemingly correctly, that an association between comparator stimuli is necessary for comparator stimuli to compete with each other for potential to compete with X.

The present experiments are consistent with many recent studies that call into question fundamental assumptions of TER theories. More specifically, considerable data suggest that animals can learn about redundant (e.g., blocked) CSs, but fail to express this learning at test (e.g., Blaisdell,
Gunther, \& Miller, 1999). Additionally troublesome for these theories is the observation that nonzero total error across all cues present on a given trial is not necessary for learning to occur, or even the expression of learning, as evidenced by recent observations of counteractions between cue competition treatments (e.g., Urcelay \& Miller, 2006). In conclusion, the present results question the view that learning is related directly to error correction based on all cues present on a given trial and are consistent with the view that behavioral control is determined in part by retrieval processes at the time of test.

\section{AUTHOR NOTE}

The research was supported by National Institute of Mental Health Grant 33881. The authors thank Patricia Di Lorenzo, Bridget L. McConnell, Heather T. Sissons, Deanne Westerman, and Daniel S. Wheeler for their comments on an earlier version of the manuscript. This research was conducted in partial fulfillment of J.E.W.'s master's degree. Requests for information concerning this research should be addressed to R. R. Miller, Department of Psychology, SUNY Binghamton, Binghamton, NY 13902-6000 (e-mail: rmiller@binghamton.edu).

\section{REFERENCES}

Blaisdell, A. P., Gunther, L. M., \& Miller, R. R. (1999). Recovery from blocking achieved by extinguishing the blocking CS. Animal Learning \& Behavior, 27, 63-76.

Denniston, J. C., Savastano, H. I., \& Miller, R. R. (2001). The extended comparator hypothesis: Learning by contiguity, responding by relative strength. In R. R. Mowrer \& S. B. Klein (Eds.), Handbook of contemporary learning theories (pp. 65-117). Mahwah, NJ: Erlbaum.

Espinet, A., Iraola, J. A., Bennett, C. H., \& Mackintosh, N. J. (1995). Inhibitory association between neutral stimuli in flavor-aversion conditioning. Animal Learning \& Behavior, 23, 361-368.

KAMIN, L. J. (1968). "Attention-like" processes in classical conditioning. In M. R. Jones (Ed.), Miami Symposium on the Prediction of Behavior: Aversive stimulation (pp. 9-33). Coral Gables, FL: University of Miami Press.

KREMER, E. (1978). The Rescorla-Wagner model: Losses in associative strength in compound conditioned stimuli. Journal of Experimental Psychology: Animal Behavior Processes, 4, 22-36.

Rescorla, R. A., \& Wagner, A. R. (1972). A theory of Pavlovian conditioning: Variations in the effectiveness of reinforcement and nonreinforcement. In A. H. Black \& W. F. Prokasy (Eds.), Classical conditioning II: Current research and theory (pp. 64-99). New York: Appleton-Century-Crofts.

Rumelhart, D. E., Hinton, G. E., \& Williams, R. J. (1986). Learning internal representations by error propagation. In D. E. Rumelhart, J. L. McClelland, \& the PDP Research Group (Eds.), Parallel distributed processing: Explorations in the microstructure of cognition. Vol. 1: Foundations (pp. 319-364). Cambridge, MA: MIT Press.

Schachtman, T. R., Kasprow, W. J., Chee, M. A., \& Miller, R. R. (1985). Blocking but not conditioned inhibition results when an added stimulus is reinforced in compound with multiple pretrained stimuli. American Journal of Psychology, 98, 283-295.

Stout, S. C., \& Miller, R. R. (2007). Sometimes-competing retrieval (SOCR): A formalization of the comparator hypothesis. Psychological Review, 114, 759-783.

Urcelay, G. P., \& Miller, R. R. (2006). Counteraction between overshadowing and degraded contingency treatments: Support for the extended comparator hypothesis. Journal of Experimental Psychology: Animal Behavior Processes, 32, 21-32.

Wheeler, D. S., \& Miller, R. R. (in press). Determinants of cue interactions. Behavioral Processes.

(Manuscript received August 1, 2007; revision accepted for publication December 18, 2007.) 